Article

\title{
Characterization of Porous Structures of Cellulose Nanofibrils Loaded with Salicylic Acid
}

\author{
Birgitte Hjelmeland McDonagh ${ }^{1}$ and Gary Chinga-Carrasco ${ }^{2, *}$ (i) \\ 1 SINTEF Industry, P.O. Box 4760 Torgarden, 7034 Trondheim, Norway; birgitte.mcdonagh@sintef.no \\ 2 RISE PFI, Høgskoleringen 6b, 7491 Trondheim, Norway \\ * Correspondence: gary.chinga.carrasco@rise-pfi.no; Tel.: +47-9083-6045
}

Received: 5 October 2020; Accepted: 27 October 2020; Published: 30 October 2020

\begin{abstract}
Bleached and unbleached pulp fibers were treated with 2,2,6,6-tetramethylpyperidine-1-oxyl (TEMPO) mediated oxidation to obtain cellulose nanofibrils (CNFs). The resulting bleached and unbleached CNFs were mixed with salicylic acid $(0,5,10,20 \mathrm{wt} \%)$ before casting and freeze-drying or 3D-printing. A series of methods were tested and implemented to characterize the CNF materials and the porous structures loaded with salicylic acid. The CNFs were characterized with atomic force microscopy and laser profilometry, and release of salicylic acid was quantified with UV-visible absorbance spectroscopy, conductivity measurements, and inductive coupled plasma mass spectrometry (ICP-MS). Fourier-transform infrared spectroscopy (FTIR) complemented the analyses. Herein, we show that aerogels of bleached CNFs yield a greater release of salicylic acid, compared to CNF obtained from unbleached pulp. The results suggest that biodegradable constructs of CNFs can be loaded with a plant hormone that is released slowly over time, which may find uses in small scale agricultural applications and for the private home market.
\end{abstract}

Keywords: nanocellulose; scaffolds; chemical elicitor; plant resistance; pesticide

\section{Introduction}

Defending crops against airborne pathogens and insects is a multimillion dollar industry that has severe impacts on the environment and human health [1]. The major reason for its environmental impact is use of non-specific chemicals that are toxic to a range of microorganisms as well as terrestrial and aquatic animals [2]. It is of imperative importance to develop green pesticides that provide healthy and nutritious crops that at the same time reduce the environmental impact of industrialized agriculture. One strategy to solve this problem could be to take advantage of the plants' own defense system and exploit existing signaling pathways to strengthen the plants' resistance to pathogens and abiotic stresses.

Plants are protected against attack from phytopathogens and fungi mainly through bark, waxy cuticle layers, and cell walls. Other exogeneous factors such as UV-radiation, salinity, extreme temperatures, and drought also have an impact on the plants' ability to grow and bear fruiting bodies [3]. In addition to structural defense mechanisms, plants can trigger an inducible immune system when exposed to external threats. The strongest immune response is effector-triggered immunity (ETI). Molecules involved in ETI can be referred to as phytohormones, and include salicylic acid, ethylene, and jasmonic acid [4]. In particular, salicylic acid plays a critical role in a parallel resistance pathway called systemic acquired resistance (SAR). This pathway is non-specific and long-lasting, and protects the plant against a broad range of microorganisms [5]. This means that when a plant is infected by a pathogen, the SAR response ensures that non-infected and distal plant tissue is warned about the incoming threat and causes upregulation of a large number of pathogenesis-related genes [6]. 
Salicylic acid can be administered exogenously through the rooting system via the soil medium. Salicylic acid is taken up by plants through roots, and has been shown to alleviate salt stress and promote growth both under saline and non-saline conditions [7,8]. Salicylic acid has also been shown to promote flowering $[9,10]$, as well as protect plants from toxic effects of insecticides [11], and reduce uptake of toxic ions $[12,13]$. This means that salicylic acid can act as a plant defense chemical when administered through the soil medium. However, salicylic acid is not used today as an alternative pesticide, most likely because of its cost and inability to absorb across cuticle layers. Because of its cost, salicylic acid must be administered locally and preferably directly to the soil with a system that can release salicylic acid over time. This requires a porous vehicle that can easily be loaded with salicylic acid and release it once in contact with soil. Methods to characterize release of salicylic acid are thus required and this is part of the motivation of the present study.

Cellulose nanofibrils (CNFs) can be applied for forming porous vehicles for salicylic acid. CNFs are obtained from lignocellulosic biomass and is a biodegradable material $[14,15]$. Various studies have demonstrated that CNFs have diameters of less than $100 \mathrm{~nm}$ and lengths in the micrometer-scale [16-20]. Due to their particular characteristics, CNFs can create stable and highly porous structures that can be embedded with drugs or chemicals through chemical modification, purification, and adequate manufacturing [21,22]. CNFs therefore offer a unique platform as a soil degradable material with drug delivery abilities.

The aim of this study was to characterize two different TEMPO CNFs, from unbleached and bleached kraft pulp fibers and describe how the CNFs can be applied to form three-dimensional porous structures to release salicylic acid as a model elicitor molecule. Unbleached pulp was used as comparison to bleached pulp, as unbleached pulp requires less processing steps during production, the pulp fibers are thus cheaper than bleached pulp fibers, and most probably would have better performance in life cycle assessments, which is also environmentally beneficial. One of the specific goals of the study was to develop characterization methods to quantify release of salicylic acid that will be applied in ongoing and future plant growth trials.

\section{Materials and Methods}

\subsection{Materials}

Salicylic acid (ACS reagent $\geq 99.0 \%$, CAS: 247588-500g) was purchased from Sigma Aldrich (Saint-Louis, Missouri, MI, USA). The raw material for production of CNFs was bleached and unbleached Pinus radiata pulp fibers provided by CMPC (Nacimiento, Chile). The content of cellulose, hemicellulose, and lignin of the unbleached pulp was $80.9,12.7$, and $6.4 \%$, respectively. The content of cellulose, hemicellulose, and lignin of the bleached pulp was $87,12.2$, and $0.8 \%$, respectively [23].

\subsection{Production and Characterization of CNFs}

The pulp fibers (bleached and unbleached) were treated with TEMPO-mediated oxidation, using 6 mmol sodium hypochlorite $(\mathrm{NaClO}$, concentration $9 \%) / g$ dry matter content cellulose. TEMPO and $\mathrm{NaBr}$ were dissolved in water and added to the pulp. $\mathrm{NaClO}$ was added and dropwise addition of $0.5 \mathrm{M} \mathrm{NaOH}$ was used to maintain the $\mathrm{pH}$ at 10 . The reaction time was approx. $60 \mathrm{~min}$, until the $\mathrm{pH}$ was constant. For details see [24]. The pre-treated fibers were homogenized with an Ultra-turrax equipment (IKA ${ }^{\circledR}$-Werke GmbH \& Co. KG, Staufen, Germany) for 6 min at 24,000 rpm. The concentration of the $\mathrm{CNFs}$ dispersion was $2 \mathrm{wt} \%$. The CNFs from the bleached pulp are hereafter referred to as bleached $\mathrm{CNFs}$, while the ones based on unbleached pulp are referred to as unbleached CNFs.

Conductometric titration was applied to quantify the carboxylic acid content, following the procedure described by Saito and Isogai [24]. An automatic titrator was applied (Metrohm 902 Titrando, Evenwood, UK) and the carboxyl groups content was estimated from the titration curve.

Laser profilometry (LP, IVT-Lehmann Messtechnikk AG, BielBiene, Switzerland) of CNF films was performed to assess the fibrillation degree. CNF dispersions of $0.2 \mathrm{wt} \%$ were casted in Petri dishes to 
form films $\left(20 \mathrm{~g} / \mathrm{m}^{2}\right)$ and allowed to dry for 5-7 days at ambient conditions. Samples $(20 \mathrm{~mm} \times 10 \mathrm{~mm})$ were mounted on objective microscopy slides with double-sided tapes and coated with a layer of gold. Ten images $(1000 \mu \mathrm{m} \times 1000 \mu \mathrm{m}$, resolution $1 \mu \mathrm{m} / \mathrm{px})$ from each sample (unbleached and bleached CNFs films) were acquired with the Laser Profilometry system. The images were processed with the ImageJ program (version 1.53b, National Institute of Health, Kansas, MI, USA) and the surface roughness at various lateral wavelengths was quantified with the SurfCharJ plugin (version 1q, Trondheim, Norway).

The nano-morphology of the CNFs was analyzed with a Veeco multimode V (Bruker Instruments, Billerica, MA, USA) at room temperature.Atomic force Microscopy (AFM) tips (SA-air) with a spring constant $\sim 0.4 \mathrm{~N} \mathrm{~m}^{-1}$ were purchased from Bruker AFM (Billerica, MA, USA). Freshly cleaved mica was attached to a magnetic stub with double-sided tape. Top layers of mica were then removed before sample application. Twenty-five microliters of diluted CNFs (MQ-water, $0.5 \mathrm{wt} \%$ ) were applied to mica and dried at room temperature overnight before analysis. Height and peak force error data were collected at a resolution of 1024 samples/line with an aspect ratio equal to 1 .

\subsection{Characterization of CNFs Loaded with Salicylic Acid}

Loading of salicylic acid was performed by mixing salicylic acid $(0,5,10,20 \mathrm{wt} \%)$ directly with the CNFs hydrogel. The CNFs-salicylic acid mixtures $(0.3 \mathrm{~g})$ were added to 96 -well plates with three replicates for each salicylic acid concentration. Samples were then frozen $\left(-20^{\circ} \mathrm{C}\right)$ and lyophilized (freeze-drying). Samples were weighed after freeze-drying before measuring release of salicylic acid in MilliQ-water.

Fourier-transform infrared spectroscopy (FTIR) was conducted on freeze-dried samples to assess the unbleached and bleached CNFs and loaded with $20 \mathrm{wt} \%$ salicylic acid. The FTIR was a Frontier, FTIR Spectrometer fitted with a universal ATR (UATR) sampling accessory, by Perkin Elmer (Waltham, MA, USA). The infrared spectra were collected in the range of $800-4000 \mathrm{~cm}^{-1}$.

Unbleached and bleached CNFs with and without salicylic acid $(10 \mathrm{wt} \%)$ were printed with a Regemat3D printing unit to test the forming of porous constructs with controlled 3D structure. The constructs consisted of 4 layers with a target height of $2 \mathrm{~mm}$. The lateral dimensions were $20 \times 40 \mathrm{~mm}$.

The freeze-dried structures (3D printed or casted) were sputtered with a layer of gold and assessed with SEM (Hitachi scanning electron microscope, SU3500, Hitachi High-Tech Corporation, Tokyo, Japan), in secondary electron imaging mode, using an acceleration voltage of $5 \mathrm{kV}$ and working distance of 5-10 $\mathrm{mm}$. Samples were cut, and mounted with the lateral side facing upwards, to show internal porosity.

\subsection{Quantification of Release of Salicylic Acid}

A time-dependent release study was conducted by adding CNFs with salicylic acid to MilliQ-water $(0.2 \mathrm{mg} \mathrm{CNFs} / \mathrm{mL})$ and measuring the conductivity as a function of time for $24 \mathrm{~h}$. A standard curve of salicylic acid was prepared for UV-vis spectroscopy ( $\lambda$ abs $=297 \mathrm{~nm}$ ) with a Shimadzu UV 1800 (Shimadzu Schweiz GmbH, Reinach BL, Switzerland). At the end-point $(\mathrm{t}=24 \mathrm{~h})$ the supernatant was measured with UV-vis spectroscopy at $\lambda \mathrm{abs}=297 \mathrm{~nm}$ and the amount of salicylic acid released after $24 \mathrm{t} h$ was calculated based on the standard curve.

Endpoint samples were also analyzed for sodium content with Inductive Coupled plasma-mass spectrometry (ICP-MS) to subtract sodium contribution from conductivity measurements. The ICP-MS instrument was a MS Triple Quad, Agilent-8800, by Agilent (Santa Clara, CA, USA). 


\section{Results and Discussion}

\subsection{Characterization of Bleached and Unbleached CNFs}

TEMPO-mediated oxidation is used to oxidize the C6 hydroxylic groups to carboxylic acid moieties on the cellulose backbone. TEMPO-mediated oxidation is more efficient on bleached cellulose [25], as lignin reduces the reaction time and thus the oxidation levels [26]. After TEMPO-mediated oxidation the cellulose nanofibrils will have a higher carboxyl group content, compared to nanofibrils that have been produced without chemical pretreatment [27]. The carboxylic acids are negatively charged at $\mathrm{pH}$ above the $\mathrm{pKa}$, i.e., the charge density increases, causing electrostatic repulsion between nanofibrils and this increases the degree of fibrillation [28]. A cellulose sample with more lignin residues would impair TEMPO-oxidation efficiency and reduce charge density. As shown in Table 1, bleached CNFs showed a higher carboxyl group content (average charge) than unbleached CNFs, and this is most likely an effect of increased lignin content in the latter [23]. With a less efficient TEMPO-oxidation the overall charge density and electrostatic repulsion is smaller which in turn is likely to affect the degree of fibrillation.

Table 1. Carboxyl group contents of bleached and unbleached cellulose nanofibrils (CNFs).

\begin{tabular}{ccc}
\hline Sample Name & Carboxyl Content $(\mu \mathrm{mol} / \mathrm{g})$ & Standard Deviation $(\mu \mathrm{mol} / \mathrm{g})$ \\
\hline Unbleached CNFs & 1057 & 18.4 \\
Bleached CNFs & 1376 & 23.5 \\
\hline
\end{tabular}

Laser profilometry has previously been applied to quantify the degree of fibrillation of CNFs materials, represented by an estimation of the amount of residual fibers [29]. A rougher surface of air-dried CNFs films means that there are a larger fraction of residual fibers and thus less fraction of cellulose nanofibrils [29]. Laser profilometry images and roughness analysis (Figure 1) show that unbleached CNFs have a rougher surface than bleached CNFs which indicates a lower degree of fibrillation and confirms a larger fraction of residual fibers.
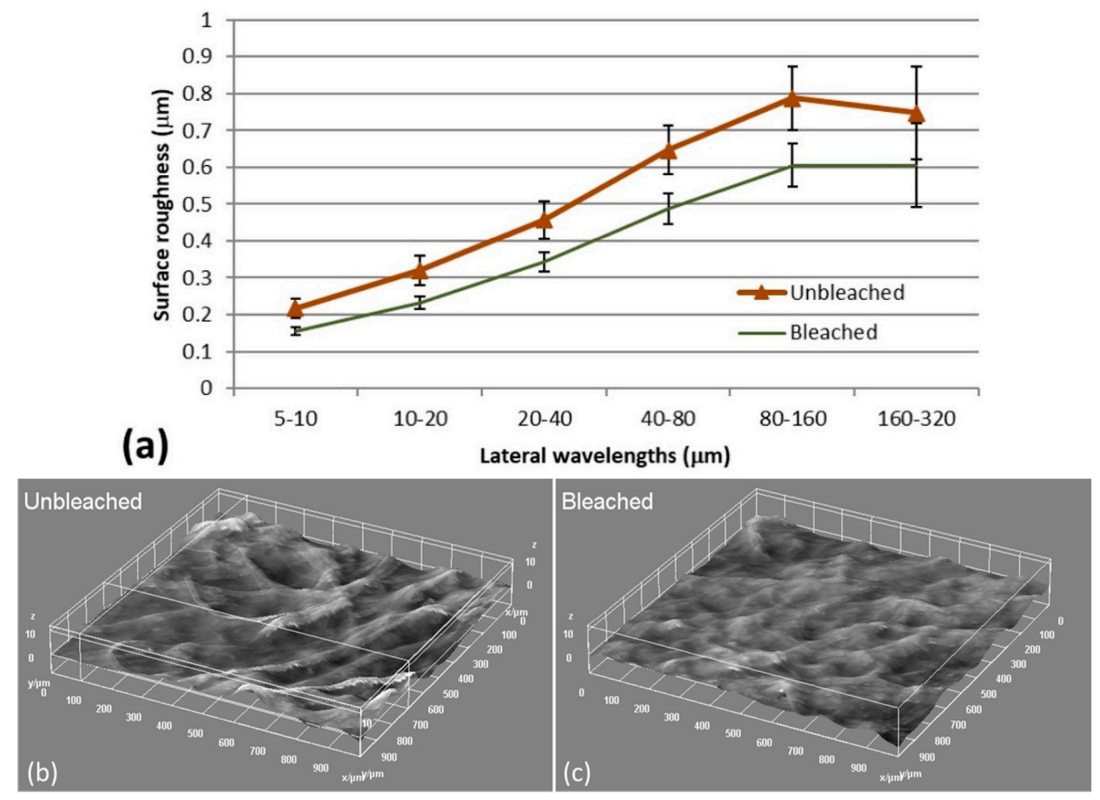

Figure 1. (a) Surface roughness analysis on films prepared from bleached and unbleached CNFs showed that the latter had a higher surface roughness than the former. The roughness values are given with the corresponding standard deviation, $n=10$. Representative laser profilometry images of unbleached (b) and bleached samples (c) show how residual fibers contribute to the roughness for the CNFs film. 
To further investigate the morphology of the nanofibrillated materials, the CNFs were characterized with AFM. AFM images (Figure 2) show a clear difference between the two CNFs qualities. The AFM images of bleached CNFs confirmed less occurrence of residual fibers compared to the unbleached CNFs. Consequently, bleached CNFs had a higher occurrence of nanofibrils, which is most likely an effect of higher surface charge and increased electrostatic repulsion (Figure 2).
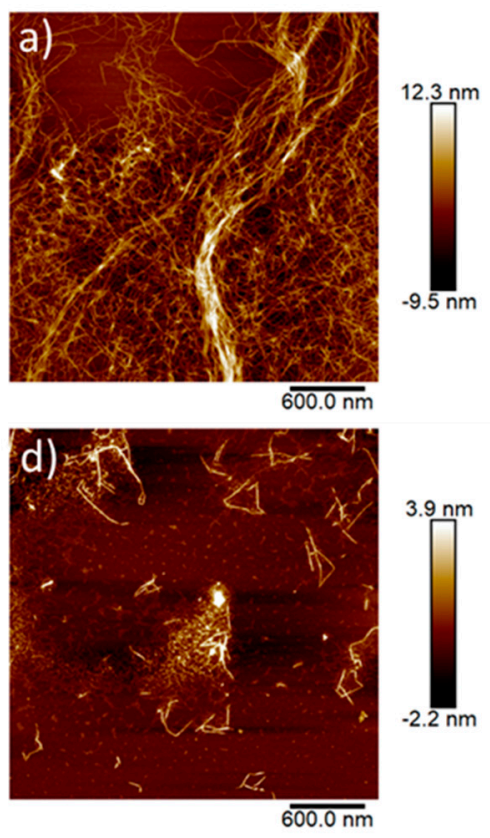
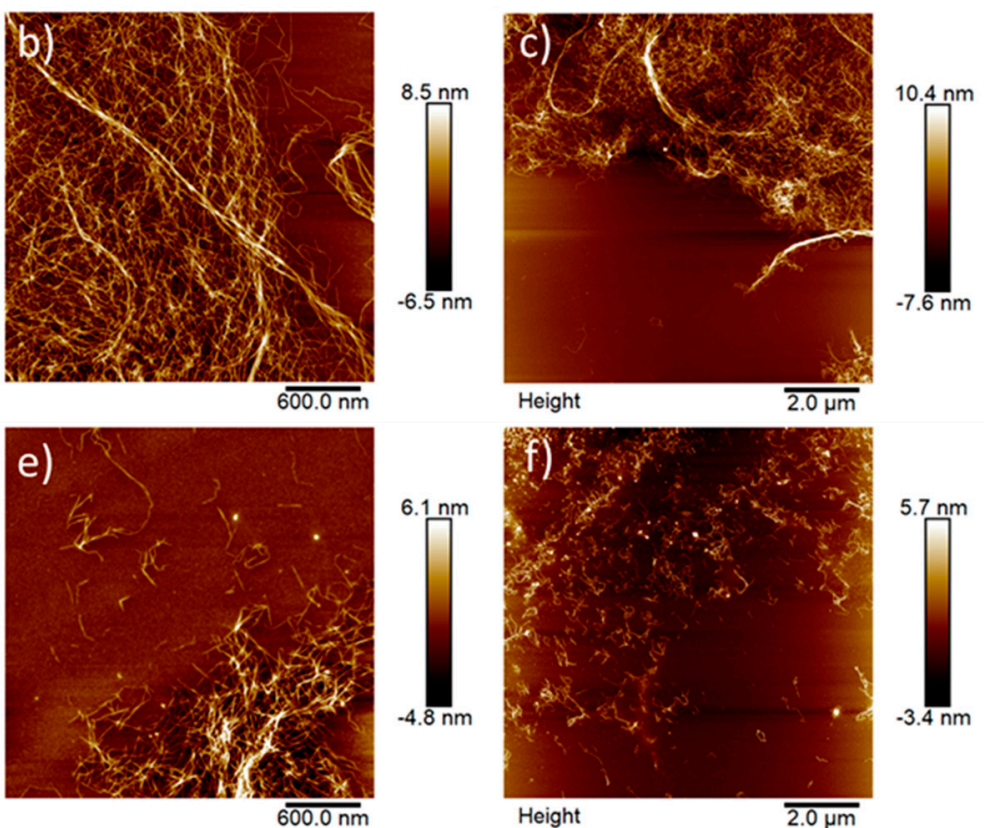

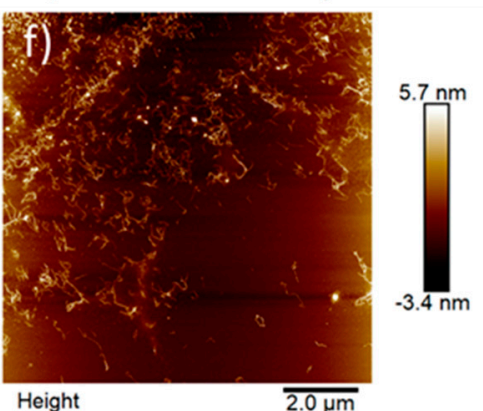

Figure 2. AFM of unbleached ((a-c) less fibrillated) and bleached ((d-f) more fibrillated) CNFs.

\subsection{Release Studies of Salicylic Acid from CNF Aerogels}

The CNF gels and aerogels from the two pulps (bleached and unbleached) are given in Figure $3 a, b$. TEMPO-mediated oxidation introduces functional groups to cellulose. The $\mathrm{pKa}, \mathrm{COOH}$ for salicylic acid is 2.97, while the pKa of C6-groups on cellulose (uronic acid) after TEMPO-oxidation is 2.8-3.7 [30]. This means that at $\mathrm{pH}$ values of $4-5$, both carboxylic groups on polyuronic acid and salicylic acid are negatively charged which leads to increased electrostatic repulsion and potentially increased release of salicylic acid. Compared to cellulose nanocrystals (CNC), CNFs have a higher flexibility and thus a greater tendency to entangle which makes the material more suitable for network formation [31]. The three-dimensional structure of CNFs can also be tailored based on the TEMPO-mediated oxidation and degree of protonation [32]. Representative SEM images of bleached and unbleached freeze-dried CNF structures are presented in Figure $3 c, d$, which exemplify the pore structure of the formed aerogels. Note the size of the pores ranging from roughly 50 to $200 \mathrm{~mm}$. Such pores are formed due to the ice crystal formation during freezing. 


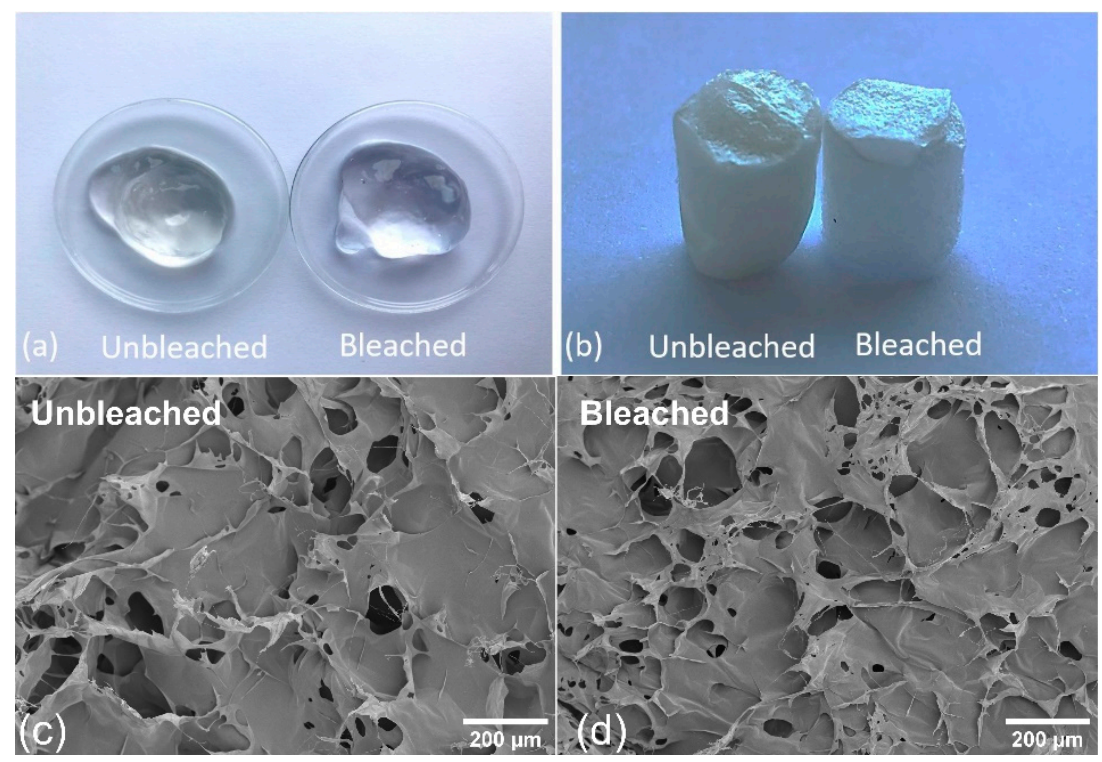

Figure 3. Images of bleached and unbleached CNFs hydrogels (a) and freeze-dried aerogels (b). The freeze-dried aerogel samples were approx. $5 \mathrm{~mm}$ in diameter and $10 \mathrm{~mm}$ in height. Note the slightly different yellow color caused by the lignin content in the unbleached CNF sample. SEM images of the unbleached (c) and bleached (d) freeze-dried aerogels. The SEM images were acquired at $100 \times$ magnification.

The most common methods to prepare CNFs aerogels are freeze-drying or critical point drying. However, more control of the macroscopic geometry can potentially be achieved through 3D-printing, which offers the possibility to tailor 3D constructs by depositing the CNFs gels layer by layer in a pre-defined shape and with a given porosity. Pores with diameters of roughly 100-200 $\mu \mathrm{m}$ are typical for these types of freeze-dried material [33]. Hence, we explored 3D printing to prepare CNFs constructs with salicylic acid as an attempt to control the structure and porosity and its effect on the release profile. Specifically, bleached and unbleached CNFs were mixed with different weight ratios of salicylic acid $(0,10$ and $20 \mathrm{wt} \%)$ before 3D-printing and freeze-drying. The 3D-printed scaffolds were characterized with SEM (Figure 4a). Note that the structures of the samples containing salicylic acid appeared to be more disrupted compared to the corresponding bleached and unbleached samples without salicylic acid (Figure 4a). This was due to the difficulties during 3D printing caused by the samples containing salicylic acid. It is however important to note that SEM images of CNFs self-assembled structures are performed on a dry material, which means that the structure is likely to be very different once dispersed in water. After characterization of the 3D-printed CNFs, the material's ability to release salicylic acid was evaluated (Figure 4b).

Release profiles of salicylic acid from 3D printed CNFs show that bleached CNFs release more salicylic acid after $24 \mathrm{~h}$ compared to unbleached CNFs (Figure $4 \mathrm{~b}$ ). This may be an effect of the differences in surface charge of the nanofibrils (Table 1). Bleached CNFs has a carboxylic acid content of $1376 \mu \mathrm{mol} / \mathrm{g}$, which is $30 \%$ higher than the carboxylic acid content of the unbleached sample. Our results show that $3 \mathrm{D}$ printed constructs of bleached CNFs released more salicylic acid than unbleached CNFs (Figure $4 b, c$ ).

It was difficult to 3D print constructs containing $10 \mathrm{wt} \%$ salicylic acid, especially for the unbleached sample. This is most probably due to the relatively large content of residual micrometer-sized fibers (Figure 2) which may block the nozzle. Hence, we put our efforts into testing aerogels that were casted and freeze-dried to assess the release profiles of salicylic acid at various ratios $(0,5,10,20 \mathrm{wt} \%)$. 

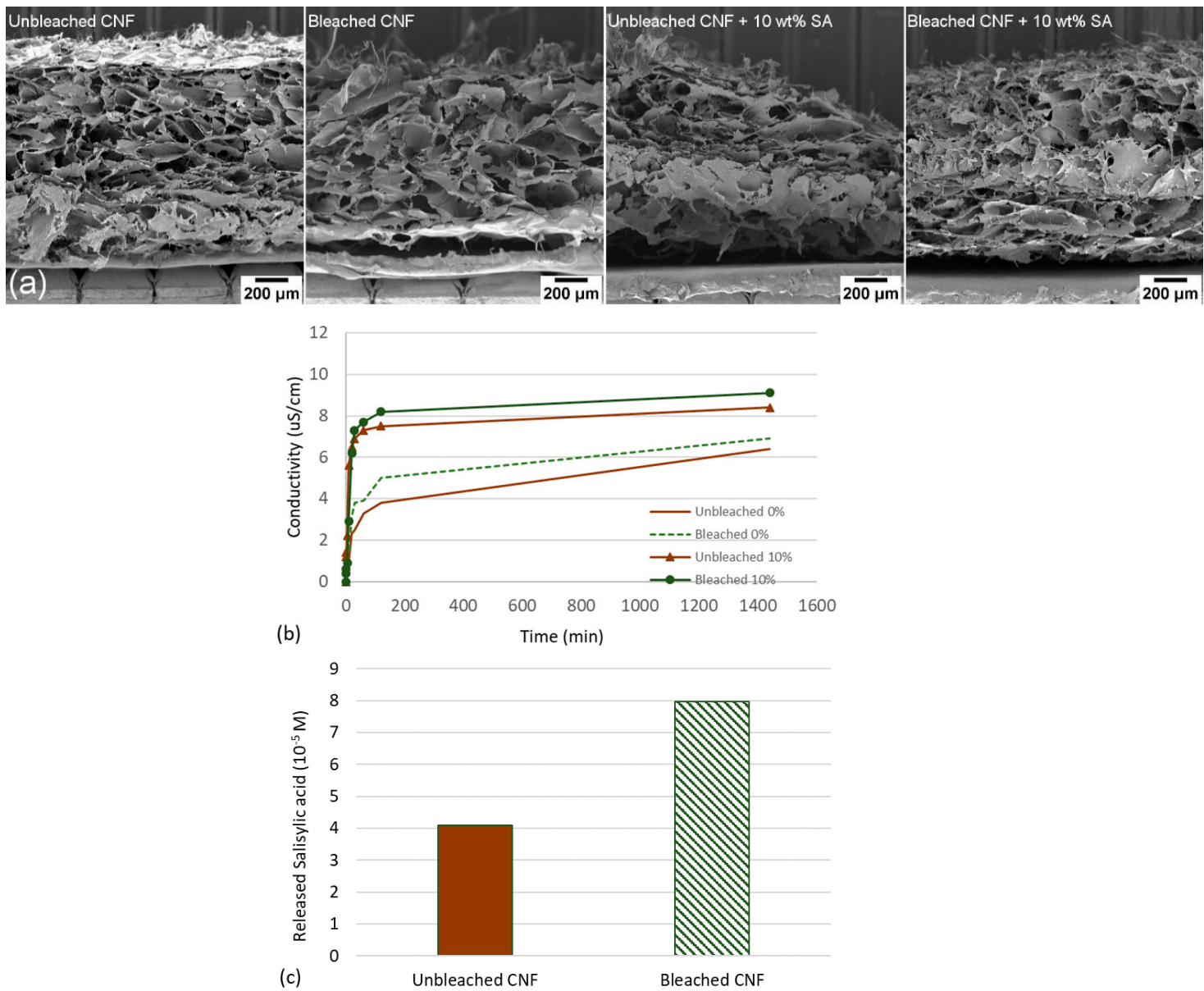

Figure 4. (a) SEM images of local regions of porous 3D printed constructs. Note the disrupted structure of the unbleached CNFs loaded with $10 \mathrm{wt} \%$ salicylic acid. (b) shows conductivity in supernatant as a function of time, while (c) shows release of salicylic acid in supernatant after $24 \mathrm{~h}$.

An FTIR analysis was performed to assess the chemical modifications of the CNF and aerogels (without and with $20 \mathrm{wt} \%$ salicylic acid) (Figure 5). Only the samples with the highest content of salicylic acid were included to secure that the content could be detectable by the FTIR system. The spectra reveal the typical peaks at 3300 and $2900 \mathrm{~cm}^{-1}$ of cellulose materials, corresponding to the stretching vibration of the $\mathrm{OH}$ and $\mathrm{CH}$ groups. The bands between 1450 and $1250 \mathrm{~cm}^{-1}$ correspond to the $\mathrm{CH}$ or $\mathrm{OH}$ bending and $\mathrm{CH}$ stretch in hemicelluloses [34]. Note that there is no evident peak at $1510 \mathrm{~cm}^{-1}$ in the assessed CNF samples. This peak has been related to the $\mathrm{C}=\mathrm{C}$ symmetrical stretching of aromatic rings that are typical of lignin [35]. This indicates that the lignin of the unbleached pulp (lignin content quantified to 6,4\%) have been reduced considerably during the TEMPO-mediated oxidation and was not detected by FTIR. We have previously demonstrated that TEMPO mediated oxidation reduces the amount of lignin considerably, confirming these findings [36]. The peak at $1610 \mathrm{~cm}^{-1}$ is attributed to the $\mathrm{C}=\mathrm{O}$ stretching vibration of carboxyl groups and is an indication of the carboxylation at the $\mathrm{C} 6$ position of the glucose unit of cellulose. The peak at $1610 \mathrm{~cm}^{-1}$ of the bleached $\mathrm{CNF}$ is more pronounced than the corresponding unbleached CNF and confirms the larger occurrence of carboxyl groups in bleached CNFs quantified by conductometric titration (Table 1). A clear difference is observed between the neat CNF samples and the samples loaded with salicylic acid, due to the reduction of CNF mass and thus an increase in transmittance. On the other side, a minor increase is detected in the peaks at $1700 \mathrm{~cm}^{-1}, 2890 \mathrm{~cm}^{-1}$, and $2920 \mathrm{~cm}^{-1}$ that have been previously reported to appear in carboxymethyl cellulose loaded with salicylic acid [37]. 

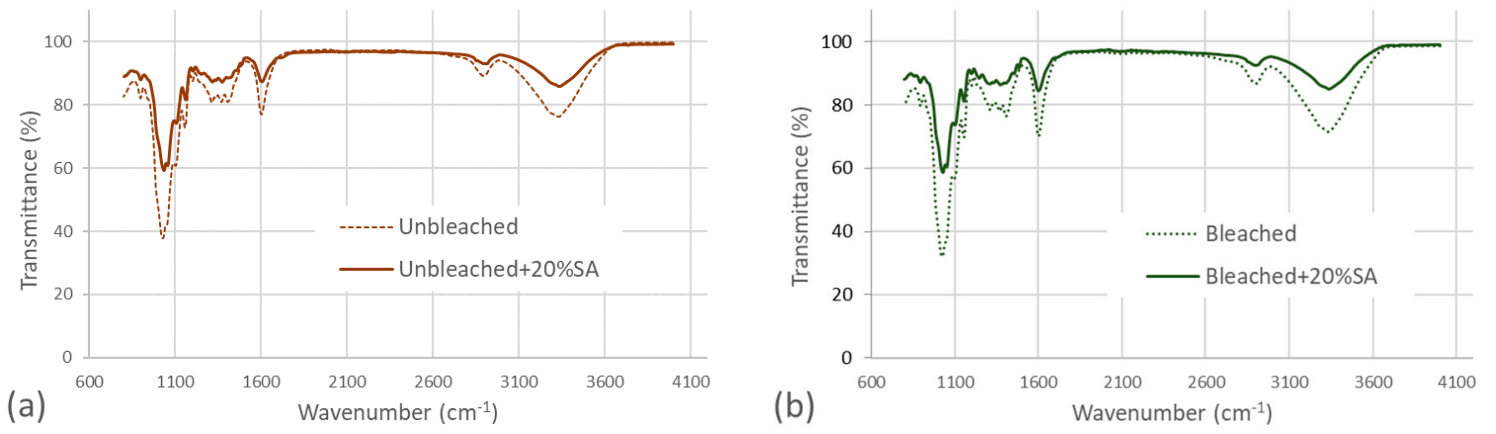

Figure 5. FTIR spectra of unbleached samples (a) and bleached samples (b).

The aerogel samples were immersed in distilled water $(\mathrm{pH}=7.0$, Conductivity $=0.9 \mu \mathrm{S} / \mathrm{cm})$ and the conductivity was measured to further study the release profile as a function of time and salicylic acid loading. When the CNFs aerogel is immersed in water it will swell and release ionic species. This outward diffusion of ions is detected as an increase in conductivity. Conductivity is a non-specific measurement, as it is not possible to distinguish which ions that are diffusing from the matrix, but it is a method to determine how rapidly charged molecules/atoms are released. In the aerogels prepared here, we expect that salicylic acid, sodium, and cellulose nanofibrils contribute to conductivity. Salicylic acid is deprotonated $(\mathrm{pKa}, \mathrm{COOH}=2.97)$ at neutral $\mathrm{pH}$ and salicylic acid and counterions would therefore contribute to increased conductivity (Figure 6a,b). Although only one sample was measured for each timepoint, the conductivity profiles follow similar trends at reasonable levels of conductivity. We thus consider the results shown in Figure $6 \mathrm{a}, \mathrm{b}$ to be reliable.
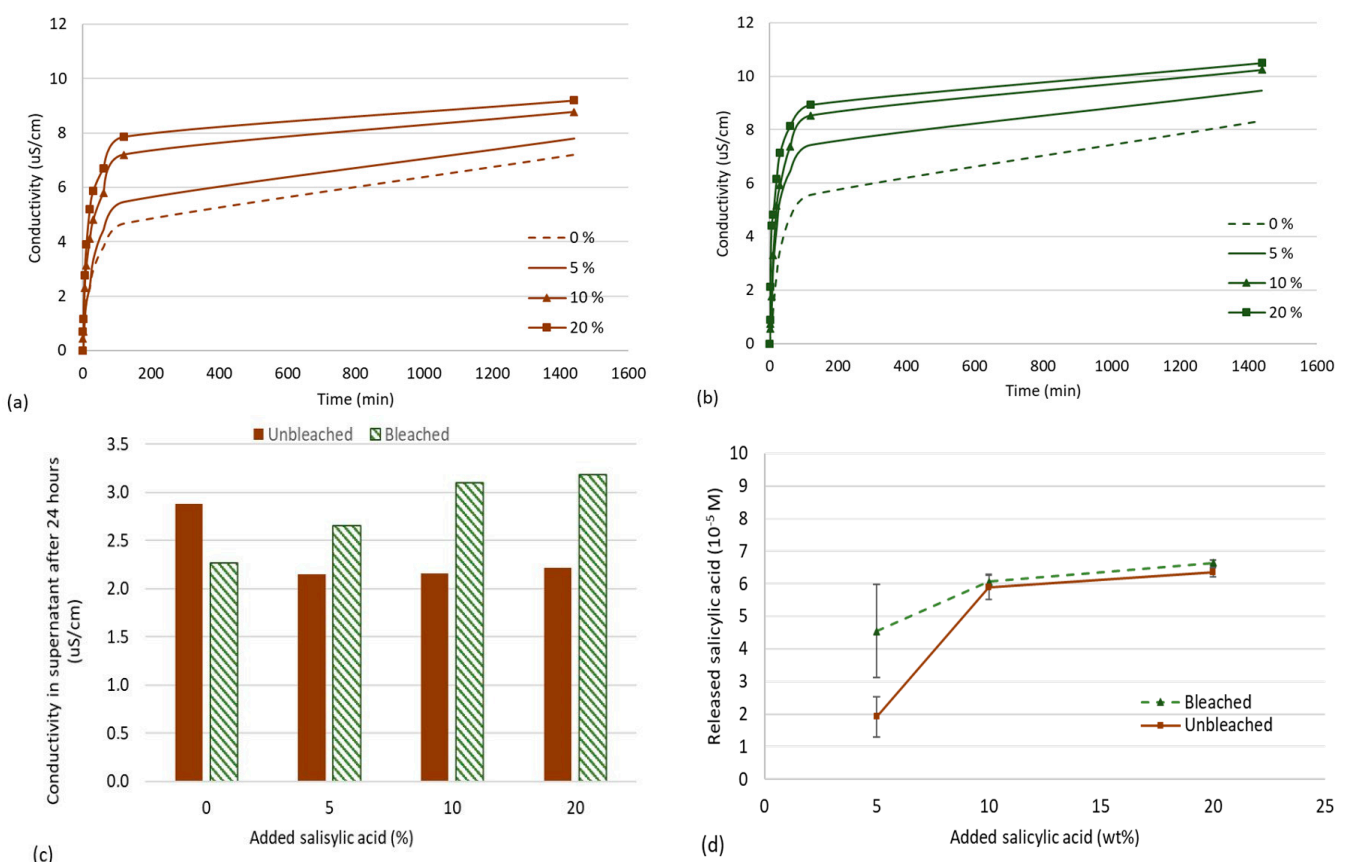

Figure 6. Conductivity measurements were performed over $24 \mathrm{~h}$ on (a) bleached CNFs and (b) unbleached CNFs loaded with 0, 5, 10, and $20 \mathrm{wt} \%$ salicylic acid. The supernatant was retrieved after $24 \mathrm{~h}$, and (c) ICP-MS was conducted on all supernatants to subtract the contribution of sodium to the conductivity, assuming that $1 \mathrm{mg} \mathrm{Na} / \mathrm{L}$ equals $2 \mu \mathrm{S} / \mathrm{cm}$. A standard curve on salicylic acid had been prepared with UV-vis spectroscopy, and (d) the supernatant after $24 \mathrm{~h}$ was analyzed with UV-vis spectroscopy $(\lambda \mathrm{abs}=297 \mathrm{~nm})$ and the corresponding concentration of salicylic acid in the supernatant was quantified. The average values in (d) are given with the corresponding standard deviation, $n=3$. 
It is also likely that the increase in conductivity is caused by oxidized cellulose nanofibrils that are released from the CNFs matrix. To elucidate which ionic species were present in the supernatant, we analyzed the supernatant for sodium with inductive coupled plasma mass spectrometry (ICP-MS). The sodium content of the supernatant was found to be highest in the bleached CNFs. Sodium is a counter ion for the carboxylic groups after TEMPO-mediated oxidation. Sodium contribution was then subtracted from the conductivity measurements to give an indication of the concentration of other ions in the supernatant. All bleached CNFs loaded with salicylic acid had an overall higher conductivity compared to unbleached CNFs (Figure 6c), which is expected to be related to the higher surface charge of the bleached CNFs and the corresponding electrostatic repulsion with salicylic acid.

UV-visible spectroscopy was conducted to quantify salicylic acid released from the CNF aerogels (Figure 6d). The results show that salicylic acid is present in the supernatant, and that bleached CNFs releases more salicylic acid. This may be an effect of the higher charge density of bleached $\mathrm{CNFs}$, which contributes to a larger swelling of CNFs aerogels in water and thus may have caused an increased release of salicylic acid.

In this study, we have developed and tested a series of methods to characterize aerogels and the corresponding release of salicylic acid. Salicylic acid has been shown to have a beneficial effect on plants when administered exogenously $[7,8]$. However, too high levels of salicylic acid may decrease enzyme activities and inhibit uptake of ions such as potassium [38]. On the contrary, low doses of salicylic acid have been found to be more beneficial, particularly concentrations around $10^{-5} \mathrm{M}$ [39]. The values of salicylic acid released from CNF-aerogels are in this concentration range (Figure 6d), which suggests that the release of salicylic acid may be sufficient. Further work will thus focus on the testing of CNF aerogels loaded with salicylic acid and their effects on plant health.

\section{Conclusions}

We prepared porous structures of CNFs embedded with a plant hormone. A series of methods were implemented and their suitability to characterize the porous structures and the release of salicylic acid was demonstrated. The results of this study indicate that increased surface charge leads to a higher release of salicylic acid, probably due to electrostatic repulsion. The release profile was assessed, and we quantified that roughly $6.5 \times 10^{-5} \mathrm{M} \mathrm{SA}$ was released after $24 \mathrm{~h}$ from the porous CNFs aerogels. We propose that biodegradable constructs of CNFs can be loaded with a plant hormone that is released slowly over time, which suggests uses in small scale agricultural applications and in the private home market.

Author Contributions: Conceptualization, G.C.-C. and B.H.M.; methodology, G.C.-C. and B.H.M.; writing-original draft preparation, G.C.-C. and B.H.M.; writing-review and editing, G.C.-C. and B.H.M.; visualization, G.C.-C. and B.H.M.; project administration, G.C.-C.; funding acquisition, G.C.-C. All authors have read and agreed to the published version of the manuscript.

Funding: The Research Council of Norway is acknowledged for funding (Grant no. 284300) and the SUSFOOD2 ERA-NET program (Grant SPAREC). The Research Council of Norway is acknowledged for the support given to the Norwegian Micro- and Nano-Fabrication Facility, NorFab, project number 245963/F50.

Acknowledgments: Mirjana Filipovic and Johnny Kvakland Melbø (RISE PFI) are acknowledged for excellent assistance in the laboratory work. Peter Molesworth (SINTEF) is acknowledged for performing the FTIR measurements on the bleached and unbleached CNFs with and without SA.

Conflicts of Interest: The authors declare no conflict of interest.

\section{References}

1. Cocco, P. Pesticides and Human Health; Oxford University Press: Oxford, UK, 2016.

2. Di Fiori, E.; Pizarro, H.; dos Santos Afonso, M.; Cataldo, D. Impact of the invasive mussel Limnoperna fortunei on glyphosate concentration in water. Ecotoxicol. Environ. Saf. 2012, 81, 106-113. [CrossRef] [PubMed] 
3. Khan, M.I.R.; Fatma, M.; Per, T.S.; Anjum, N.A.; Khan, N.A. Salicylic acid-induced abiotic stress tolerance and underlying mechanisms in plants. Front. Plant Sci. 2015, 6, 462. [CrossRef]

4. Bektas, Y.; Eulgem, T. Synthetic plant defense elicitors. Front. Plant Sci. 2015, 5, 804. [CrossRef]

5. Balakireva, A.V.; Zamyatnin, A.A. Indispensable Role of Proteases in Plant Innate Immunity. Int. J. Mol. Sci. 2018, 19, 629. [CrossRef]

6. Durrant, W.E.; Dong, X. SYSTEMIC ACQUIRED RESISTANCE. Annu. Rev. Phytopathol. 2004, 42, 185-209. [CrossRef]

7. Arfan, M.; Athar, H.R.; Ashraf, M. Does exogenous application of salicylic acid through the rooting medium modulate growth and photosynthetic capacity in two differently adapted spring wheat cultivars under salt stress? J. Plant Physiol. 2007, 164, 685-694. [CrossRef] [PubMed]

8. Nazar, R.; Umar, S.; Khan, N.A. Exogenous salicylic acid improves photosynthesis and growth through increase in ascorbate-glutathione metabolism and $\mathrm{S}$ assimilation in mustard under salt stress. Plant Signal. Behav. 2015, 10, e1003751. [CrossRef] [PubMed]

9. Hayat, Q.; Hayat, S.; Irfan, M.; Ahmad, A. Effect of exogenous salicylic acid under changing environment: A review. Environ. Exp. Bot. 2010, 68, 14-25. [CrossRef]

10. Raskin, I. Role of Salicylic Acid in Plants. Annu. Rev. Plant Physiol. Plant Mol. Biol. 1992, 43, $439-463$. [CrossRef]

11. Singh, H.; Singh, N.B.; Singh, A.; Hussain, I. Exogenous Application of Salicylic Acid to Alleviate Glyphosate Stress in Solanum lycopersicum. Int. J. Veg. Sci. 2017, 23, 552-566. [CrossRef]

12. Agami, R.A.; Mohamed, G.F. Exogenous treatment with indole-3-acetic acid and salicylic acid alleviates cadmium toxicity in wheat seedlings. Ecotoxicol. Environ. Saf. 2013, 94, 164-171. [CrossRef] [PubMed]

13. Yang, Z.-M.; Wang, J.; Wang, S.-H.; Xu, L.-L. Salicylic acid-induced aluminum tolerance by modulation of citrate efflux from roots of Cassia tora L. Planta 2003, 217, 168-174. [CrossRef]

14. Kangas, H.; Pitkänen, M.; Vikman, M.; Vartiainen, J.; Tsitko, I. Biodegradability, Compostability and Safety of Cellulose Nanofibrils (CNF) and CNF Based Products. In Proceedings of the TAPPI International Conference on Nanotechnology for Renewable Materials Proceedings, Atlanta, GA, USA, 22-25 June 2015.

15. Vikman, M.; Vartiainen, J.; Tsitko, I.; Korhonen, P. Biodegradability and Compostability of Nanofibrillar Cellulose-Based Products. J. Polym. Environ. 2015, 23, 206-215. [CrossRef]

16. Chinga-Carrasco, G.; Yu, Y.D.; Diserud, O. Quantitative Electron Microscopy of Cellulose Nanofibril Structures from Eucalyptus and Pinus radiata Kraft Pulp Fibers. Microsc. Microanal. 2011, 17, 563-571. [CrossRef] [PubMed]

17. Fukuzumi, H.; Saito, T.; Isogai, A. Influence of TEMPO-oxidized cellulose nanofibril length on film properties. Carbohydr. Polym. 2013, 93, 172-177. [CrossRef]

18. Gamelas, J.A.F.; Pedrosa, J.; Lourenco, A.F.; Mutje, P.; Gonzalez, I.; Chinga-Carrasco, G.; Singh, G.; Ferreira, P.J.T. On the morphology of cellulose nanofibrils obtained by TEMPO-mediated oxidation and mechanical treatment. Micron 2015, 72, 28-33. [CrossRef] [PubMed]

19. Mattos, B.D.; Tardy, B.L.; Rojas, O.J. Accounting for Substrate Interactions in the Measurement of the Dimensions of Cellulose Nanofibrils. Biomacromolecules 2019, 20, 2657-2665. [CrossRef]

20. Shinoda, R.; Saito, T.; Okita, Y.; Isogai, A. Relationship between Length and Degree of Polymerization of TEMPO-Oxidized Cellulose Nanofibrils. Biomacromolecules 2012, 13, 842-849. [CrossRef]

21. Bhandari, J.; Mishra, H.; Mishra, P.K.; Wimmer, R.; Ahmad, F.J.; Talegaonkar, S. Cellulose nanofiber aerogel as a promising biomaterial for customized oral drug delivery. Int. J. Nanomed. 2017, 12, 2021. [CrossRef]

22. Zhao, J.Q.; Lu, C.H.; He, X.; Zhang, X.F.; Zhang, W.; Zhang, X.M. Polyethylenimine-Grafted Cellulose Nanofibril Aerogels as Versatile Vehicles for Drug Delivery. ACS Appl. Mater. Interfaces 2015, 7, 2607-2615. [CrossRef]

23. Chinga-Carrasco, G.; Kuznetsova, N.; Garaeva, M.; Leirset, I.; Galiullina, G.; Kostochko, A.; Syverud, K. Bleached and unbleached MFC nanobarriers: Properties and hydrophobisation with hexamethyldisilazane. J. Nanopart. Res. 2012, 14, 1280. [CrossRef]

24. Saito, T.; Isogai, A. TEMPO-mediated oxidation of native cellulose. The effect of oxidation conditions on chemical and crystal structures of the water-insoluble fractions. Biomacromolecules 2004, 5, 1983-1989. [CrossRef] [PubMed]

25. Isogai, A.; Saito, T.; Fukuzumi, H. TEMPO-oxidized cellulose nanofibers. Nanoscale 2011, 3, 71-85. [CrossRef] [PubMed] 
26. Ehman, N.V.; Lourenco, A.F.; McDonagh, B.H.; Vallejos, M.E.; Felissia, F.E.; Ferreira, P.J.T.; Chinga-Carrasco, G.; Area, M.C. Influence of initial chemical composition and characteristics of pulps on the production and properties of lignocellulosic nanofibers. Int. J. Biol. Macromol. 2020, 143, 453-461. [CrossRef]

27. Heggset, E.B.; Chinga-Carrasco, G.; Syverud, K. Temperature stability of nanocellulose dispersions. Carbohydr. Polym. 2017, 157, 114-121. [CrossRef]

28. Geng, L.; Mittal, N.; Zhan, C.; Ansari, F.; Sharma, P.R.; Peng, X.; Hsiao, B.S.; Söderberg, L.D. Understanding the Mechanistic Behavior of Highly Charged Cellulose Nanofibers in Aqueous Systems. Macromolecules 2018, 51, 1498-1506. [CrossRef]

29. Chinga-Carrasco, G.; Averianova, N.; Kondalenko, O.; Garaeva, M.; Petrov, V.; Leinsvang, B.; Karlsen, T. The effect of residual fibres on the micro-topography of cellulose nanopaper. Micron 2014, 56, 80-84. [CrossRef]

30. Fujisawa, S.; Okita, Y.; Fukuzumi, H.; Saito, T.; Isogai, A. Preparation and characterization of TEMPO-oxidized cellulose nanofibril films with free carboxyl groups. Carbohyd. Polym. 2011, 84, 579-583. [CrossRef]

31. De France, K.J.; Hoare, T.; Cranston, E.D. Review of Hydrogels and Aerogels Containing Nanocellulose. Chem. Mater. 2017, 29, 4609-4631. [CrossRef]

32. Jiang, F.; Hsieh, Y.-L. Self-assembling of TEMPO Oxidized Cellulose Nanofibrils As Affected by Protonation of Surface Carboxyls and Drying Methods. ACS Sustain. Chem. Eng. 2016, 4, 1041-1049. [CrossRef]

33. Syverud, K.; Kirsebom, H.; Hajizadeh, S.; Chinga-Carrasco, G. Cross-linking cellulose nanofibrils for potential elastic cryo-structured gels. Nanoscale Res. Lett. 2011, 6, 1-6. [CrossRef]

34. Chaikumpollert, O.; Methacanon, P.; Suchiva, K. Structural elucidation of hemicelluloses from Vetiver grass. Carbohyd. Polym. 2004, 57, 191-196. [CrossRef]

35. Sanchez-Gutierrez, M.; Espinosa, E.; Bascon-Villegas, I.; Perez-Rodriguez, F.; Carrasco, E.; Rodriguez, A. Production of Cellulose Nanofibers from Olive Tree Harvest-A Residue with Wide Applications. Agronomy 2020, 10, 696. [CrossRef]

36. Chinga-Carrasco, G.; Ehman, N.V.; Pettersson, J.; Vallejos, M.E.; Brodin, M.W.; Felissia, F.E.; Hakansson, J.; Area, M.C. Pulping and Pretreatment Affect the Characteristics of Bagasse Inks for Three-dimensional Printing. ACS Sustain. Chem. Eng. 2018, 6, 4068-4075. [CrossRef]

37. Rozali, M.L.H.; Ahmad, Z.; Isa, M.I.N. Interaction between Carboxy Methylcellulose and Salicylic Acid Solid Biopolymer Electrolytes. Adv. Mater. Res. 2015, 1107, 223-229. [CrossRef]

38. Harper, J.R.; Balke, N.E. Characterization of the Inhibition of $\mathrm{K}^{+}$; Absorption in Oat Roots by Salicylic Acid. Plant Physiol. 1981, 68, 1349. [CrossRef]

39. Fariduddin, Q.; Hayat, S.; Ahmad, A. Salicylic Acid Influences Net Photosynthetic Rate, Carboxylation Efficiency, Nitrate Reductase Activity, and Seed Yield in Brassica juncea. Photosynthetica 2003, 41, 281-284. [CrossRef]

Publisher's Note: MDPI stays neutral with regard to jurisdictional claims in published maps and institutional affiliations.

(C) 2020 by the authors. Licensee MDPI, Basel, Switzerland. This article is an open access article distributed under the terms and conditions of the Creative Commons Attribution (CC BY) license (http://creativecommons.org/licenses/by/4.0/). 